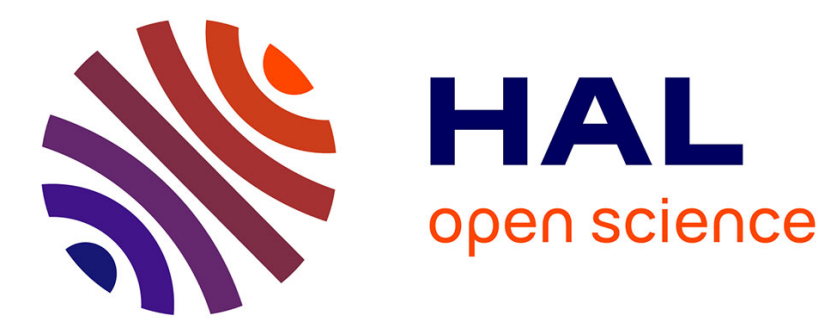

\title{
Optimal Power Flow for Large-Scale Power System with Shunt FACTS using Efficient Parallel GA
}

Belkacem Mahdad, Kamel Srairi, Tarek Bouktir, Mohamed Benbouzid

\section{To cite this version:}

Belkacem Mahdad, Kamel Srairi, Tarek Bouktir, Mohamed Benbouzid. Optimal Power Flow for Large-Scale Power System with Shunt FACTS using Efficient Parallel GA. IEEE IECON'08, Nov 2008, Orlando, United States. pp.867-972. hal-00531283

\section{HAL Id: hal-00531283 \\ https://hal.science/hal-00531283}

Submitted on 2 Nov 2010

HAL is a multi-disciplinary open access archive for the deposit and dissemination of scientific research documents, whether they are published or not. The documents may come from teaching and research institutions in France or abroad, or from public or private research centers.
L'archive ouverte pluridisciplinaire HAL, est destinée au dépôt et à la diffusion de documents scientifiques de niveau recherche, publiés ou non, émanant des établissements d'enseignement et de recherche français ou étrangers, des laboratoires publics ou privés. 


\title{
Optimal Power Flow for Large-Scale Power System with Shunt FACTS using Efficient Parallel GA
}

\author{
B. Mahdad, K. Srairi, T. Bouktir and M.E.H. Benbouzid, Senior Member, IEEE
}

\begin{abstract}
This paper presents an efficient parallel GA (EPGA) for the solution of large scale OPF. The decomposition procedure decomposes the original problem into several interacting sub problems that can be solved with smaller sub populations and coordinate the solution of these sub problems to achieve the solution of the whole problem, the length of the original chromosome is reduced successively based on the decomposition level and adapted with the topology of the new partition. Partial decomposed active power demand added as a new variable and searched within the active power generation variables of the new decomposed chromosome. The strategy of the OPF problem is decomposed in two sub-problems, the first sub-problem related to active power planning to minimize the fuel cost function, and the second sub-problem designed to make corrections to the voltage deviation and reactive power violation based in an efficient reactive power planning of multi Static Var Compensator (SVC). Numerical results on two test systems IEEE 30-bus and IEEE 118-bus are presented and compared with results of others competitive global approach. The results show that the approach proposed can converge to the optimum solution, and obtains the solution with high accuracy.
\end{abstract}

Key words - Optimal Power Flow, Large scale, Genetic algorithm, Fuzzy logic, Shunt Compensators, FACTS, Reactive sensitivity index.

\section{INTRODUCTION}

$\mathrm{T}$ HE main objective of an OPF strategy is to determine the optimal operating state of a power system by optimizing a particular objective while satisfying certain specified physical and operating constraints. In its most general formulation, the OPF is a nonlinear, nonconvex, large-scale, static optimization problem with both continuous and discrete control variables. The presence of discrete control variables, such as switch able shunt devices, transformer tap positions, and phase shifters, further complicates the problem solution [1-4].

The global optimization techniques known as genetic algorithms (GA), simulated annealing (SA), tabu search (TS), and evolutionary programming (EP), which are the forms of probabilistic heuristic algorithm have been successfully used to overcome the non-convexity problems of the constrained ED [5]. The GA method has usually better efficiency because the GA has parallel search techniques. Due to its high

B. Mahdad an K. Srairi are with the Department of Electrical Engineering, University of Biskra, Algeria, BP 145 Biskra University (email: bemahdad@yahoo.fr / ksrairi@yahoo.fr).

T. Bouktir is with the Department of Electrical Engineering, Oum Elbouaghi University, Algeria,(e-mail: tbouktir@yahoo.fr).

M.E.H. Benbouzid is with the Laboratoire d'Ingénierie Mécanique et Electrique (LIME), IUT of Brest, University of Western Brittany, France. potential for global optimization, GA has received great attention in solving optimal power flow (OPF) problems.

The literature on the application of the global optimization in the OPF problem is vast and [6] represents the major contributions in this area. In [7] authors present an enhanced genetic algorithm (EGA) for the solution of the OPF problem with both continuous and discrete control variables. The continuous control variables modeled are unit active power outputs and generator-bus voltage magnitudes, while the discrete ones are transformer-tap settings and switchable shunt devices. With the aid of the problem specific operators proposed the efficiency and the accuracy of the solution are enhanced. In [8] the authors proposed a simple genetic algorithm and evolutionary programming applied to the OPF problem in large-scale power systems. To accelerate the processes of the optimization, the controllable variables are decomposed to active and passive constraints. The active constraints are taken to minimize the fuel cost function; the passive constraints are taken and integrated to an efficient power flow problem to make corrections to the active power of the slack bus.

It is clear from the methods cited in the literature that they require improvement of the CPU execution time to be integrated to the online practical large-scale network.

This paper presents an efficient parallel GA (EPGA) coordinated with an efficient reactive power planning based shunt FACTS Compensators known as SVC to enhance the solution of the optimal power flow and to improve the power system security.

\section{OPTIMAL POWER FLOW FORMULATION}

The active power planning problem is considered as a general minimization problem with constraints, and can be written in the following form:

$$
\begin{array}{cc}
\text { Min } & f(x, u) \\
\text { S.t } & : g(x, u)=0 \\
& h(x, u) \leq 0 \\
x=\left[\begin{array}{ll}
\delta & V_{L}
\end{array}\right]^{T} \\
u=\left[\begin{array}{llll}
P_{G} & V_{G} & t & B_{s v c}
\end{array}\right]^{T}
\end{array}
$$

$\mathrm{f}(\mathrm{x}, \mathrm{u})$ is the objective function, $\mathrm{g}(\mathrm{x}, \mathrm{u})$ and $\mathrm{h}(\mathrm{x}, \mathrm{u})$ are respectively the set of equality and inequality constraints. $\mathrm{x}$ is the state variables and $u$ is the vector of control variables. The control variables are generator active and reactive power outputs, bus voltages, shunt capacitors/reactors and transformers tap-setting. The state variables are voltage and angle of load buses. For optimal active power dispatch, the objective function $f$ is total generation cost as expressed follows: 


$$
\operatorname{Min} f=\sum_{i=1}^{N_{g}}\left(a_{i}+b_{i} P_{g i}+c_{i} P_{g i}^{2}\right)
$$

Where $N_{g}$ is the number of thermal units, $P_{g i}$ is the active power generation at unit $\mathrm{i}$ and $a_{i}, b_{i}$ and $c_{i}$ are the cost coefficients of the $i^{\text {th }}$ generator.

The equality constraints $g(x)$ are the power flow equations, expressed as follows:

$$
\begin{array}{r}
P_{g i}-P_{d i}-\sum_{j=1}^{N}\left|V_{i}\right|\left|V_{j} \| Y_{i j}\right| \cos \left(\delta_{i}-\delta_{j}-\delta_{i j}\right)=0 \\
\text { and } Q_{g i}-Q_{d i}-\sum_{j=1}^{N}\left|V_{i}\right|\left|V_{j} \| Y_{i j}\right| \sin \left(\delta_{i}-\delta_{j}-\delta_{i j}\right)=0
\end{array}
$$

The inequality constraints $h(x)$ reflect the limits on physical devices in the power system as well as the limits created to ensure system security:

- Upper and lower limits on the active and reactive generations:

$$
\begin{gathered}
P_{g i}^{\min } \leq P_{g i} \leq P_{g i}^{\max } \\
Q_{g i}^{\min } \leq Q_{g i} \leq Q_{g i}^{\max }
\end{gathered}
$$

- Upper and lower bounds on the tap ratio (t) and phase shifting ( $a$ ) of variable transformers:

$$
\begin{aligned}
& t_{i j}^{\min } \leq t_{i j} \leq t_{i j}^{\max } \\
& \alpha_{i j}^{\min } \leq \alpha_{i j} \leq \alpha_{i j}^{\max }
\end{aligned}
$$

- Upper limit on the active power flow $\left(P_{i j}\right)$ of line i-j.

$$
\left|P_{i j}\right| \leq P_{i j}^{\max }
$$

- Upper and lower bounds in the bus voltage magnitude:

$$
V_{i}^{\min } \leq V_{i} \leq V_{i}^{\max }
$$

- Upper and lower bounds in the Shunt FACTS parameters

$$
X^{\min }<X_{\text {FACTS }}<X^{\max }
$$

\section{SHUNT FACTS MODELIZATION}

\section{A. Static VAR Compensator (SVC)}

The steady-state model proposed in [9] is used here to incorporate the SVC on power flow problems. This model is based on representing the controller as a variable impedance, assuming an SVC configuration with a fixed capacitor (FC) and Thyristor-controlled reactor (TCR) as depicted in Figure 1. Applying simultaneously a gate pulse to all thyristor of a thyristor valve brings the valve into conduction. The valve will block approximately at the zero crossing of the ac current, in the absence of firing signals. Thus, the controlling element is the Thyristor valve. The thyristors are fired symmetrically, in an angle control range of 90 to 180 with respect to the capacitor (inductor) voltage.

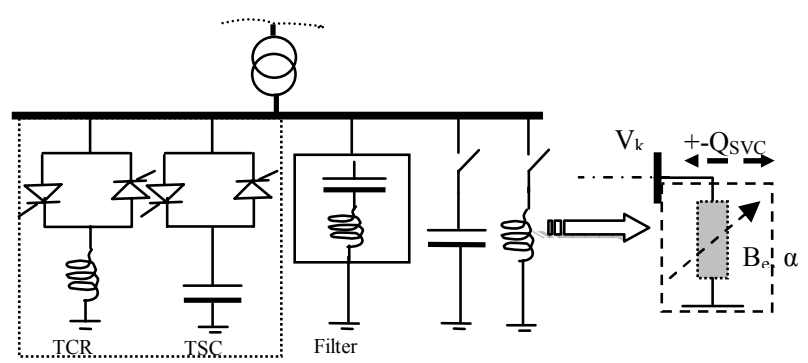

Fig. 1. SVC steady-state circuit representation

$$
V=V_{\text {ref }}+X_{s l} I
$$

$\mathrm{X}_{\mathrm{sl}}$ are in the range of 0.02 to 0.05 p.u. with respect to the SVC base. The slope is needed to avoid hitting limits. At the voltage limits the SVC is transformed into a fixed reactance. The total equivalent impedance $\mathrm{Xe}$ of SVC may be represented by

$$
X_{e}=X_{C} \frac{\pi / k_{X}}{\sin 2 \alpha-2 \alpha+\pi\left(2-1 / k_{X}\right)}
$$

where $k_{X}=X_{C} / X_{L}$

\section{Strategy OF The EfFicient PARAllel GA For OPF}

\section{A. Principle of the Approach Proposed}

Parallel execution of various SGAs is called PGA (Parallel Genetic Algorithm). Parallel Genetic Algorithms (PGAs) have been developed to reduce the large execution times that are associated with simple genetic algorithms for finding nearoptimal solutions in large search spaces. They have also been used to solve larger problems and to find better solutions. PGAs can easily be implemented on networks of heterogeneous computers or on parallel mainframes. The way in which GAs can be parallelized depends upon the following elements [10]:

How fitness is evaluated.

How selection is applied locally or globally.

How genetic operators (crossover and mutation are used and applied)

If single or multiple subpopulations are used.

If multiple populations are used how individuals are exchanged.

How to coordinate between different subpopulations to save the proprieties of the original chromosome.

The various methods of PGA are:

- Independent PGA

- Migration PGA

- Partition PGA

- Segmentation PGA

- Segmentation-Migration PGA

In the approach proposed the subpopulations created are dependent, efficient load flow used as a simple tool for flexible coordination to test the performance of the new subpopulations generated.

Fig. 2 presents the principal of the efficient parallel GA approach for active power planning coordinated with reactive power planning to adjust the voltage source and reactive 
power compensation within their specified constraints limits to reduce voltage deviation and the thermal transmission line. The controllable FACTS devices considered include shunt compensators (SVC).

The proposed algorithm decomposes the solution of such a modified OPF problem into two linked sub problems. The first subproblem is an active power generation planning solved by the proposed Efficient Genetic Algorithm, and the second subproblem is a reactive power planning [11-12] to make fine adjustments on the optimum values obtained from the EPGA. This will provide updated voltages, angles and point out generators having exceeded reactive limits.

\section{B. Decomposition Mechanism}

Problem decomposition is an important task for large-scale OPF problem, which needs answers to the following two technical questions.

1- How many efficient partitions needed?

2- Where to practice and generate the efficient interindependent sub-systems?

The decomposition procedure decomposes a problem into several interacting sub-problem that can be solved with reduced sub-populations, and coordinate the solution processes of these sub-problems to achieve the solution of the whole problem.

\section{Justification for using Efficient Parallel Continuous GA}

\section{1) Standard Genetic Algorithm}

GA is a global search technique based on mechanics of natural selection and genetics. It is a general-purpose optimization algorithm that is distinguished from conventional optimization techniques by the use of concepts of population genetics to guide the optimization search. Instead of point-to-point search, GA searches from population to population. The advantages of GA over traditional techniques are [13]:

i) It needs only rough information of the objective function and places no restriction such as differentiability and convexity on the objective function.

ii) The method works with a set of solutions from one generation to the next, and not a single solution, thus making it less likely to converge on local minima.

iii) The solutions developed are randomly based on the probability rate of the genetic operators such as mutation and crossover; the initial solutions thus would not dictate the search direction of GA.

\section{2) Review of the Modified GA Applied to the OPF} Problem

\section{a) Adaptive GA}

For better results and to get faster convergence, conventional GA modes have been modified. In recent years various techniques have been studied to achieve this objective, these include:

-Using advanced string coding.

-Generating initial population with some prior knowledge.

-Establishing some better evaluation function.
-Including new operators such as elitism, multi point or uniform crossover and creep mutation. A refined GA was used to solve the economic dispatch in [14] and a pyramid Genetic Algorithm (PGA) has been used in [15-16] for voltage profile

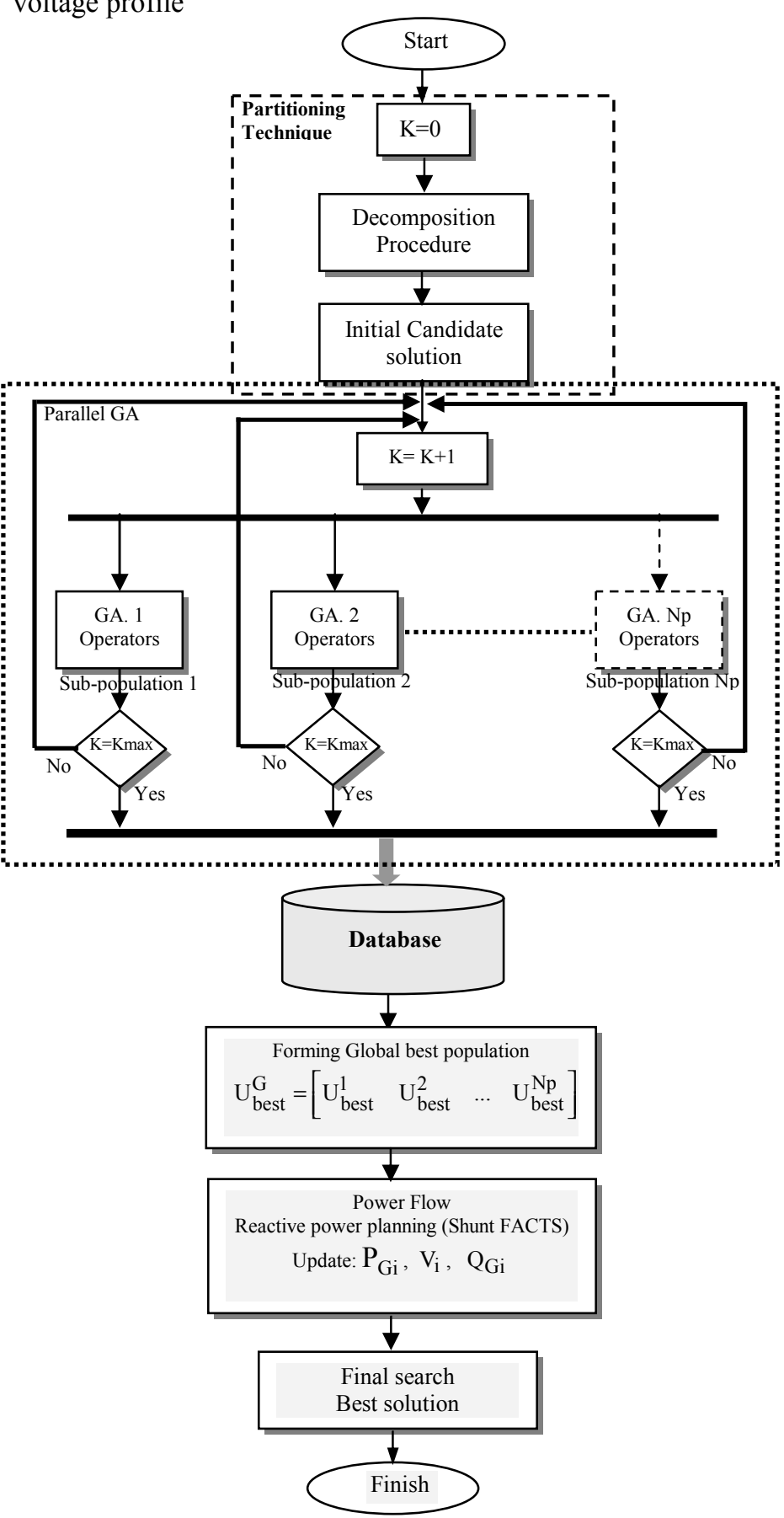

Fig. 2. Flowchart of the proposed EPGA approach-based OPF

optimization. Fig. 3 illustrates the basic principal of the adaptive GA based in Genetic parameters adjustments. 


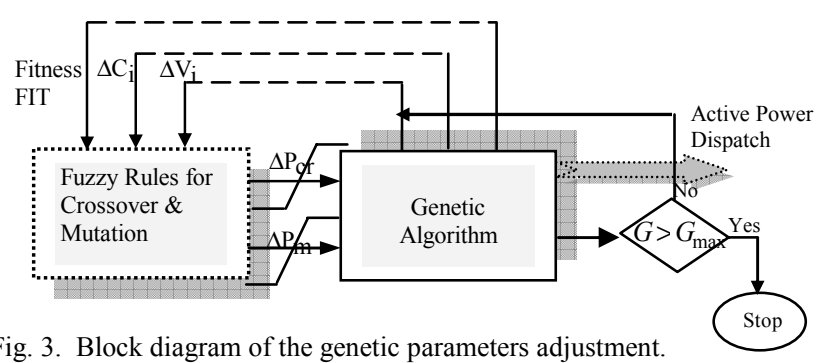

3) Continuous GA Applied to the OPF Problem

The binary GA has its precision limited by the binary representation of variables; using floating point numbers instead easily allows representation to the machine precision. This continuous GA also has the advantage of requiring less storage than the binary GA because a single floating-point number represents the variable instead of $\mathrm{N}_{\text {bits }}$ integers. The continuous GA is inherently faster than the binary GA, because the chromosomes do not have to be decoded prior to the evaluation of the cost function [13]. Fig. 4 shows the chromosome structure within the approach proposed.

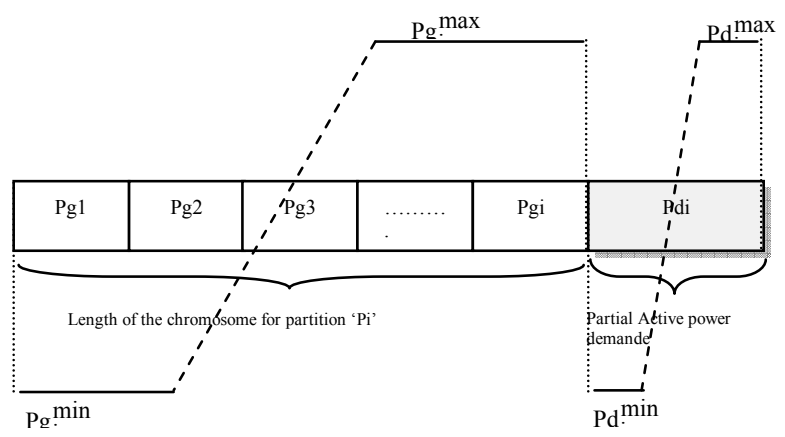

Fig. 4. Chromosome structure.

\section{a) Algorithm of the Approach Proposed}

\section{Initialization based in decomposition Procedure}

The main idea of the proposed approach is to optimize the active power demand for each partitioned network to minimize the total fuel cost. An initial candidate solution generated for the global $\mathrm{N}$ population size.

1-For each decomposition level estimate the initial active power demand:

For $\mathrm{NP}=2$ Do

$$
\begin{aligned}
& P d 1=\sum_{i=1}^{M 1} P_{G i} \\
& P d 2=\sum_{i=1}^{M 2} P_{G i}=P D-P d 1
\end{aligned}
$$

Where NP the number of partition

$P d 1$ : the active power demand for the first initial partition.

$P d 2$ : the active power demand for the second initial partition.

$P D$ : the total active power demand for the original network.

The following equilibrium equation should be verified for each decomposed level:

For level 1:

$$
P d 1+P d 2=P D+\text { Ploss }
$$

2-Fitness Evaluation based Load Flow

For all sub-systems generated perform a load flow calculation to evaluate the proposed fitness function. A candidate solution formed by all sub-systems is better if its fitness is higher.

$$
\begin{aligned}
& f_{i}=1 /\left(F_{\cos t}-a_{l} F_{l i}-a_{V} F_{V i}\right) \\
& F_{V i}=\sum_{j=1}^{n P Q}\left(V_{P Q i j}-V_{P Q i j}^{\lim } \mid\right) /\left(V_{P Q i j}^{\max }-V_{P Q i j}^{\min }\right)
\end{aligned}
$$

where $f_{i}$ is the fitness function for sub systems decomposed at level $\mathrm{i}$.

$F_{l i}$ denotes the per unit power loss generated by sub-systems at level i; $F_{\cos t}$ denotes the total cost of the active power planning related to the decomposition level i; $F_{V i}$ denotes the sum of the normalized violations of voltages related to the sub-systems at level i.

3-Consequently under this concept, the final value of active power demand should satisfy the following equations.

$$
\begin{aligned}
& \sum_{i=1}^{N_{g}}\left(P g_{i}\right)=\sum_{i=1}^{\text {part }}\left(P d_{i}\right)+\text { ploss } \\
& P g_{i}^{\min } \leq P g_{i} \leq P g_{i}^{\max }
\end{aligned}
$$

\section{Economic Dispatch based Parallel GA}

Suppose the original network under study decomposed into S sub-systems $1,2 \ldots .$. S with PG1, PG2,.....PGN, the active power control variables, for this decomposed sub-systems related $\mathrm{S}$ sub-populations, $1,2 \ldots \ldots \mathrm{S}$, with population sizes, $\mathrm{N} 1 \ldots \ldots . . \mathrm{NS}$, and $(\mathrm{N} 1+\mathrm{N} 2+\ldots \ldots \mathrm{NS}=\mathrm{N})$.

-Each sub-population contains NP1 control variables to be optimized.

-Each sub-population updated based on the GA operators.

\section{Final Search Mechanism}

-All the sub-systems are collected to form the original network, global data base generated based on the best results Ubest (parti) found from all sub-populations.

-The final solution Ubest(Global) is found out after reactive power planning procedure to adjust the reactive power generation limits, and voltage deviation, the final optimal cost is modified to compensate the reactive constraints violations.

\section{APPLICATION STUDY}

The algorithm proposed is developed in the Matlab programming language using 6.5 version. The proposed EPGA is tested using modified IEEE 30-bus system and the standard IEEE 118-bus model. The test examples have been run on a 2.6-Ghz Pentium-IV PC. Table III shows the generators data and cost coefficients.

\section{A. Case Studies on the IEEE 30-Bus System}

The first test is the IEEE 30-bus, 41-branch system, for the voltage constraint the lower and upper limits are 0.9 p.u and 1.1 p.u., respectively.The GA population size is taken equal 30 , the maximum number of generation is 100 , and crossover and mutation are applied with initial probability 0.9 and 0.01 respectively. For the purpose of verifying the efficiency of the 
proposed approach, we made a comparison of our algorithm with others competing OPF algorithm. In [8], they presented a standard GA, in [7], the authors presented an enhanced GA, and then in [17], they proposed an Ant Colony Optimization (ACO). In [18] they presented an optimal power flow solution using GA-Fuzzy system approach. The operating cost in our approach proposed is 800.8336 and the power loss is 8.920 which are better than the others methods reported in the literature. Results in Table I show clearly that the approach proposed gives better results. Table II shows the best solution of shunt compensation obtained at the standard load demand $(\mathrm{Pd}=283.4 \mathrm{MW})$ using reactive power planning [10]. Fig. 5 demonstrates the improvement achieved in voltage profiles for the original network.

TABLE I

RESUltS OF THE Minimum COST AND POWER GENERATION COMPARED WITH SGA, EGA, ACO AND FGA FOR IEEE 30-BUs

\begin{tabular}{|c|c|c|c|c|c|c|c|}
\hline \multirow{2}{*}{ Variables } & \multicolumn{3}{|c|}{ Our Approach EPGA } & SGA $[8]$ & EGA[7] & $\mathrm{ACO}[17]$ & FGA[18] \\
\hline & $\mathrm{NP}=1$ & $\mathrm{NP}=2$ & $\mathrm{NP}=3$ & & & & \\
\hline $\mathrm{Pl}(\mathrm{MW})$ & 180.12 & 175.12 & 174.63 & 179.367 & 176.20 & 181.945 & 175.137 \\
\hline P2(MW) & 44.18 & 48.18 & 47.70 & 44.24 & 48.75 & 47.0010 & 50.353 \\
\hline $\mathrm{P} 5$ (MW) & 19.64 & 20.12 & 21.64 & 24.61 & 21.44 & 20.5530 & 21.451 \\
\hline $\mathrm{P} 8(\mathrm{MW})$ & 20.96 & 22.70 & 20.24 & 19.90 & 21.95 & 21.1460 & 21.176 \\
\hline P11(MW) & 14.90 & 12.96 & 15.04 & 10.71 & 12.42 & 10.4330 & 12.667 \\
\hline P13(MW) & 12.72 & 13.24 & 12.98 & 14.09 & 12.02 & 12.1730 & 12.11 \\
\hline Q1(Mvar) & -4.50 & -2.11 & -2.03 & -3.156 & & - & -6.562 \\
\hline Q2(Mvar) & 30.71 & 32.57 & 32.42 & 42.543 & & - & 22.356 \\
\hline Q5(Mvar) & 22.59 & 24.31 & 23.67 & 26.292 & & - & 30.372 \\
\hline Q8(Mvar) & 37.85 & 27.82 & 28.22 & 22.768 & . & - & 18.89 \\
\hline Q11(Mvar) & -2.52 & 0.490 & 0.48 & 29.923 & - & - & 21.737 \\
\hline Q13(Mvar) & -13.08 & -11.43 & -11.43 & 32.346 & - & - & 22.635 \\
\hline$\theta 1(\mathrm{deg})$ & 0.00 & 0.00 & 0.00 & 0.000 & - & - & 0.00 \\
\hline$\theta 2(\mathrm{deg})$ & -3.448 & -3.324 & -3.313 & -3.674 & - & - & -3.608 \\
\hline$\theta 5(\mathrm{deg})$ & -9.858 & -9.725 & -9.623 & -10.14 & - & - & -10.509 \\
\hline$\theta 8(\mathrm{deg})$ & -7.638 & -7.381 & -7.421 & -10.00 & & - & -8.154 \\
\hline$\theta 11(\mathrm{deg})$ & -7.507 & -7.680 & -7.322 & -8.851 & - & - & -8.783 \\
\hline$\theta 13(\mathrm{deg})$ & -9.102 & -8.942 & -8.926 & -10.13 & - & - & -10.228 \\
\hline Cost $(\$ / h r)$ & 801.3445 & 800.8336 & 800.9265 & 803.699 & 802.06 & 802.578 & 802.0003 \\
\hline $\begin{array}{l}\text { Power } \\
\text { Loss (MW) }\end{array}$ & 9.120 & 8.920 & 8.833 & 9.5177 & 9.3900 & 9.8520 & 9.494 \\
\hline
\end{tabular}

TABLE II

Comparative Results of the Shunt Reactive Power Compensation BETWEEN EPGA AND EGA [7] FOR IEEE 30-BUS

\begin{tabular}{|c|c|c|c|c|c|c|c|c|}
\hline Shunt $\mathrm{N}^{\circ}$ & 1 & 2 & 3 & 4 & 6 & 7 & 8 & 9 \\
\hline Bus $\mathrm{N}^{\circ}$ & 10 & 12 & 15 & 17 & 21 & 23 & 24 & 29 \\
\hline Best [sve [pu] & 0.1517 & 0.0781 & 0.0295 & 0.0485 & 0.0602 & 0.0376 & 0.0448 & 0.0245 \\
\hline $\begin{array}{l}\text { Besct casas bh } \\
{[\text { pul } 77]}\end{array}$ & 0.05 & 0.05 & 0.03 & 0.05 & 0.05 & 0.04 & 0.05 & 0.03 \\
\hline
\end{tabular}

The operation costs of the best solutions for the new system composed by two partitions and for the new system composed by three partitions are $800.8336 \$ / \mathrm{h}$ and 800.9265, respectively, ( 0.0929 difference). The differences between the values are not significant compared to the original network without partitioning. This proves that the new subsystems generated conserve the physical proprieties and performances of the original network.

TABLE III

GENERATOR DATA AND COST COEFFICIENTS FOR IEEE 30-Bus

\begin{tabular}{l|l|l|l|l|l}
\hline$\substack{\text { Bus } \\
\text { No }}$ & $P_{G}^{\min }$ & $P_{G}^{\max }$ & $Q_{G}^{\min }$ & $Q_{G}^{\max }$ & Cost Coefficients \\
\hline
\end{tabular}

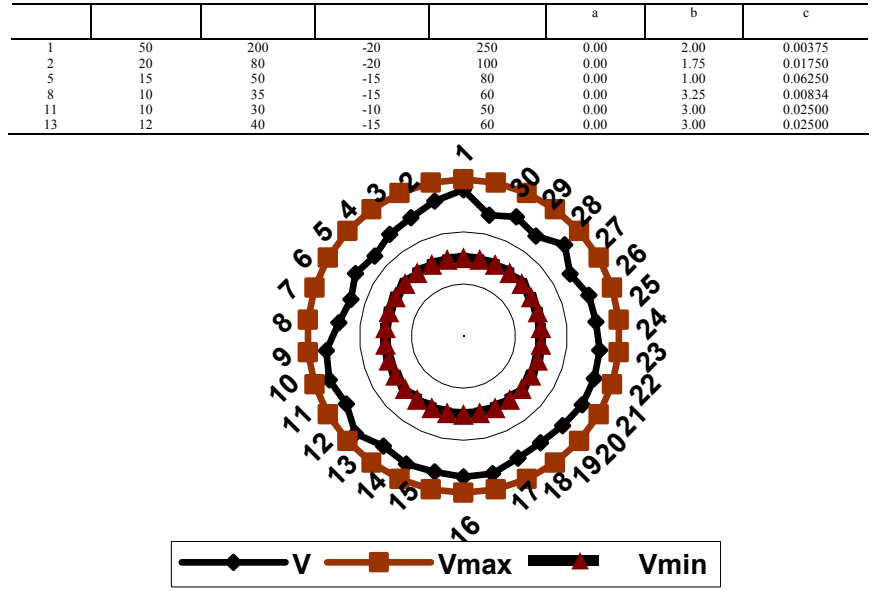

Fig. 5. Voltage profiles of IEEE 30-bus electrical network.

\section{B. Case Studies on the IEEE 118-Bus}

To investigate the computational efficiency of the proposed approach the algorithm was implemented and tested to the standard IEEE 118-bus model system (54 generators, 186 (line + transformer) and 99 loads). The system load is 4242 MW and base MVA is 100 MVA. In this model, there are 54 generators and they are consists of different 18 characteristic generators [8]. The proposed approach is compared to the real Genetic Algorithm proposed in [8]. The results depicted in Table IV show clearly that the approach proposed gives much better results than the others method. The difference in generation cost between these two studies $(6902 \$ / \mathrm{h}$ compared to $8278.9 \$ / \mathrm{h}$ ) and in real power loss $(106.66 \mathrm{MW}$ compared to $94.305 \mathrm{MW})$. In addition it is important to point out that this simple approach converges in an acceptable time. For this test system CPU time was approximately in average $12.1717 \mathrm{~s}$ for eleven subsystems.

The optimum active powers are all in their secure limits values and are far from the physical constraints limits. The security constraints are also checked for voltage magnitudes and angles. Reactive power planning [11-12] applied in the second step based in practical fuzzy rules. Fig. 6 shows that the reactive power generations are on their security limits, Fig. 7 shows the reactive power exchanged between the SVC Compensators installed at critical buses and the network. Fig. 8 demonstrates that the voltage profiles for all buses are enhanced based in reactive power planning subproblem.

TABLE IV

RESUlts OF THE MinimuM COST AND POWER GENERATION COMPARED WITH GA FOR IEEE 118-BUS

\begin{tabular}{c|ccccccc}
\hline Gen & Type & EPGA & GA $[8]$ & Gen & Type & EPGA & GA $[8]$ \\
\hline $\mathbf{1}$ & $\# 1$ & 10.840 & $\mathbf{1 1 . 9 9}$ & 65 & $\# 11$ & 402.60 & 456.61 \\
$\mathbf{4}$ & $\# 1$ & 11.280 & 33.603 & 66 & $\# 11$ & 120.06 & 134.99 \\
$\mathbf{6}$ & $\# 1$ & 16.840 & 10.191 & 69 & $\# 12$ & $\mathbf{5 2 2 . 9 6}$ & 316.59 \\
$\mathbf{8}$ & $\# 1$ & 21.380 & 10.038 & 70 & $\# 1$ & 26.700 & 24.148 \\
$\mathbf{1 0}$ & $\# 2$ & 258.86 & 162.09 & 72 & $\# 1$ & 21.940 & 31.967 \\
$\mathbf{1 2}$ & $\# 3$ & 92.760 & 63.06 & 73 & $\# 1$ & 14.040 & 43.362 \\
$\mathbf{1 5}$ & $\# 1$ & 10.000 & 28.439 & 74 & $\# 1$ & 25.480 & 10.149 \\
$\mathbf{1 8}$ & $\# 1$ & 10.000 & 10.398 & 76 & $\# 1$ & 28.020 & 16.45 \\
$\mathbf{1 9}$ & $\# 1$ & 10.780 & 10.023 & 77 & $\# 1$ & 15.820 & 12.131 \\
$\mathbf{2 4}$ & $\# 1$ & 10.060 & 13.178 & 80 & $\# 13$ & 370.54 & 445.55 \\
$\mathbf{2 5}$ & $\# 4$ & 290.08 & 282.02 & 85 & $\# 1$ & 47.260 & 18.717 \\
$\mathbf{2 6}$ & $\# 5$ & 393.36 & 376.55 & 87 & $\# 14$ & 27.400 & 44.402 \\
$\mathbf{2 7}$ & $\# 1$ & 27.720 & 29.683 & 89 & $\# 15$ & 392.38 & 322.79 \\
$\mathbf{3 1}$ & $\# 6$ & 19.780 & 67.232 & 90 & $\# 1$ & 10.000 & 20.24 \\
$\mathbf{3 2}$ & $\# 1$ & 12.940 & 14.144 & 91 & $\# 1$ & 10.000 & 21.206 \\
$\mathbf{3 4}$ & $\# 1$ & 44.160 & 12.912 & 92 & $\# 1$ & 10.000 & 19.163 \\
$\mathbf{3 6}$ & $\# 1$ & 14.620 & 12.639 & 99 & $\# 1$ & 10.000 & 10.161 \\
$\mathbf{4 0}$ & $\# 1$ & 37.240 & 66.505 & 100 & $\# 16$ & 312.88 & 318.47 \\
$\mathbf{4 2}$ & $\# 1$ & 26.160 & 19.805 & 103 & $\# 17$ & 82.840 & 47.058 \\
$\mathbf{4 6}$ & $\# 7$ & 28.660 & 13.345 & 104 & $\# 1$ & 10.000 & 39.387 \\
$\mathbf{4 9}$ & $\# 8$ & 101.24 & 217.88 & 105 & $\# 1$ & 10.000 & 18.515 \\
\hline
\end{tabular}




\begin{tabular}{c|ccccccc}
\hline $\mathbf{5 4}$ & $\# 9$ & 40.820 & 52.24 & 107 & $\# 1$ & 40.820 & 10.248 \\
$\mathbf{5 5}$ & $\# 1$ & 13.140 & 14.431 & 110 & $\# 1$ & 18.620 & 10.554 \\
$\mathbf{5 6}$ & $\# 1$ & 14.520 & 23.335 & 111 & $\# 18$ & 56.280 & 28.67 \\
$\mathbf{5 9}$ & $\# 10$ & 157.26 & 59.497 & 112 & $\# 1$ & 12.060 & 10.833 \\
$\mathbf{6 1}$ & $\# 10$ & 41.920 & 195.11 & 113 & $\# 1$ & 11.340 & 22.311 \\
$\mathbf{6 2}$ & $\# 1$ & 11.820 & 43.015 & 116 & $\# 1$ & 10.380 & 28.272 \\
\hline Cost & & $\mathbf{6 9 0 2 . 0}$ & 8278.9 & & & & \\
(\$/hr)t & & & & & & & \\
\hline & & & & & & \\
\hline Losses & & $\mathbf{1 0 6 . 6 6}$ & 94.305 & & & & \\
(MW) & & & & & & & \\
\hline
\end{tabular}

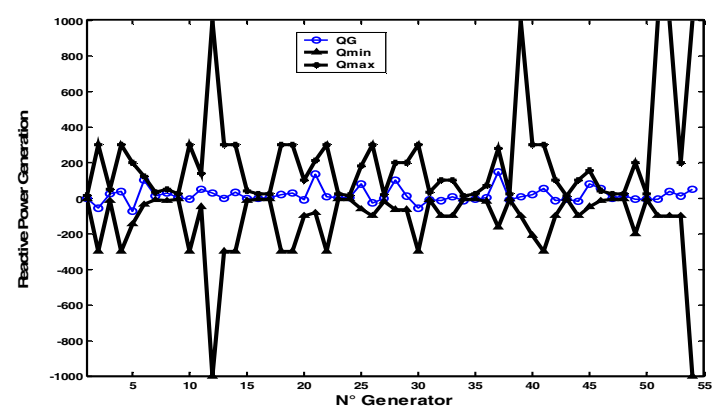

Fig. 6. Reactive power generation of IEEE 118-bus electrical network with shunt compensation $(\mathrm{Pd}=4242 \mathrm{MW})$.

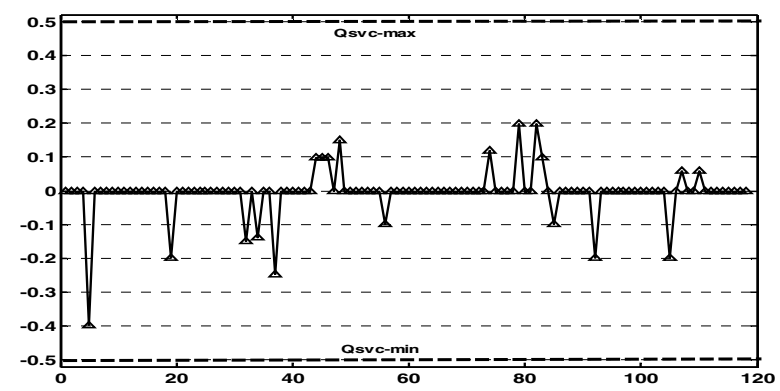

Fig. 7. Reactive power compensation based SVC Compensators exchanged with the IEEE 118-bus electrical network $(\mathrm{Pd}=4242 \mathrm{MW})$.

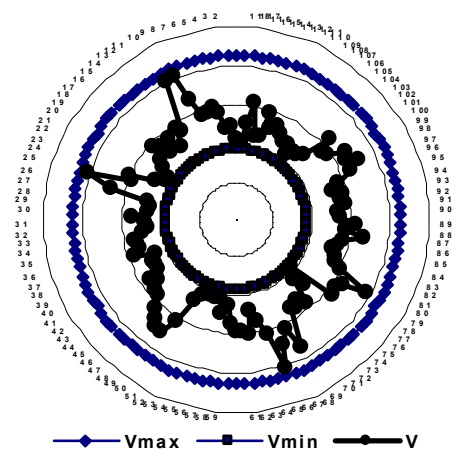

Fig. 8. Voltage profiles of IEEE 118-bus electrical network

\section{CONCLUSION}

An approach combining Efficient Parallel Genetic Algorithm (EPGA) for optimal active power planning (OAPP) and simple fuzzy logic expert rules for reactive power control (RPC) has been tested and demonstrated for large scale power system. The main objective of the approach proposed is to improve the performance of the standard GA in term of reduction time execution for an online application to large scale power system. To save an important CPU time, the original network was decomposed in multi subsystem and the problem transformed to optimize the active power demand associated to each partitioned network. The approach proposed guaranties to save the proprieties of the original network. As for the future work along this line, the author will strive to develop an adaptive and a flexible algorithm to generalize the application of the proposed approach to largescale power systems (up to 300 -Bus) and with the possibility for an online application.

\section{REFERENCES}

[1] B. Sttot and J. L. Marinho, "Linear programming for power system network security applications," IEEE Trans. Power Apparat. Syst. , vol. PAS-98, pp. 837-848, May/June 1979.

[2] O. Alsac and B. stott. "Optimal load flow with steady state security," IEEE Trans. Power Appara. Syst. , pp. 745-751, May-June 1974.

[3] M. Huneault, and F. D. Galiana, "A survey of the optimal power flow literature," IEEE Trans. Power Systems, vol. 6, no. 2, pp. 762-770, May 1991.

[4] D. Nualhong, S. Chusanapiputt, S. Phomvuttisarn, and S. Jantarang, "Reactive tabu search for optimal power flow under constrained emission dispatch," in proc IEEE, pp. 327-330, 2004.

[5] J. A. Momoh and J. Z. Zhu, "Improved interior point method for OPF problems, "IEEE Trans. Power Syst., vol. 14, pp. 1114-1120, Aug. 1999.

[6] R. C. Bansal, "Otimization methods for electric power systems: an overview," International Journal of Emerging Electric Power Systems, vol. 2, no. 1, pp. 1-23, 2005.

[7] A. G. Bakistzis, P. N. Biskas, C. E. Zoumas, and V. Petridis, "Optimal power flow by enhanced genetic algorithm, "IEEE Trans. Power Systems, vol. 17, no. 2, pp. 229-236, May 2002.

[8] T. Bouktir, L. Slimani, B. Mahdad, "Optimal power dispatch for large scale power system using stochastic search algorithms, “ Accepted at International Journal of Power and Energy Systems, Paper Number 203-3501, 2008.

[9] C. R. Feurt-Esquivel, E. Acha, Tan SG, JJ. Rico, "Efficient object oriented power systems software for the analysis of large-scale networks containing FACTS controlled branches," IEEE Trans. Power Systems, vol. 13, no. 2, pp. 464-472, May 1998.

[10] S. N. Sivanandam, S.N Deepa, Introduction to Genetic Algorithm, Springer-Verlag Berlin Heidelberg, 2008.

[11] B. Mahdad, T. Bouktir, K. Srairi, "Methodology based in practical fuzzy rules coordinated with asymetric dynamic compensation applied to the unbalanced distribution network," International Review of Electrical Engineering (IREE), vol. 3, no. 2, pp. 145-153 (2007), ISSN 1827- 6660, Praise Worthy Prize, Italy.

[12] B. Mahdad, T. Bouktir, K. Srairi, "Flexible methodology based in fuzzy logic rules for reactive power planning of multiple shunt FACTS devices to enhance system loadability," Power Engineering Society General Meeting, 2007. IEEE, 24-28 June 2007 Page(s):1 - 6, Digital Object Identifier 10.1109/PES.2007.385750.

[13] R. L. Haupt, S. E. Haupt, Practical Genetic Algorithms, $2^{\text {nd }}$ ed. Reading, John Willey \& Sons, 2004.

[14] G.B Sheble, and K. Britigg, "Refined genetic algorithm-economic dispatch exemple," IEEE Trans. Power Systems, vol. 10, no. 1, pp. 117-124, Feb. 1995.

[15] T. Yalcinoz, H. Altun, and M. Uzam, "Economic dispatch solution using genetic algorithm based on arithmetic crossover,"in Proc. IEEE Porto Power Tech. Conf., Porto, Portugal, Sep. 2001.

[16] M. Todorovski, and D. Rajičič, "An initialization procedure in solving optimal power flow by genetic algorithm," IEEE Trans. Power Systems, vol. 21, no. 2, pp. 480-487, May 2006.

[17] L. Slimani, T. Bouktir, "Economic power dispatch of power system with pollution control using multiobjective ant colony optimization, “ International Journal of Power and Computational Intelligence Research, vol. 03, no. 2, pp. 145-153, 2007.

[18] A. Saini, D. K. Chaturvedi, A. K. Saxena, "Optimal power flow soultion: a GA-Fuzzy system approach ," International Journal of Emerging Electric Power Systems, vol. 5, no. 2, pp. 1-21 (2006). 